\title{
FREE PERITONEAL FLUID IN TRAUMA PATIENTS: THE PARADIGM SHIFT
}

\author{
I. Negoi ${ }^{1,2}$, S. Păun ${ }^{1,2}$, S. Hostiuc ${ }^{1,3}$, B. Stoica ${ }^{1}$, I. Tănase ${ }^{1}$, M. Beuran ${ }^{1,2}$ \\ ${ }^{1}$ The University of Medicine and Pharmacy "Carol Davila", Bucharest, Romania \\ ${ }^{2}$ The Emergency Hospital of Bucharest, Romania \\ ${ }^{3}$ The National Institute of Legal Medicine "Mina Minovici”, Romania \\ Corresponding author: Ionuț Negoi \\ Phone no. 0040215992308 \\ E-mail: negoiionut@gmail.com
}

\begin{abstract}
Trauma surgeons are confronted nowadays with various abdominal injuries, with a more and more increased severity, secondary to urban violence and traffic related accidents. We aim to better define the prognostic value of post-traumatic hemoperitoneum (PTH) in the nowadays era of nonoperative management of abdominal lesions, and to correlate it with the current pattern of traumatic injuries. Retrospective study of patients admitted during 24 months. Selections criteria: (1) Traumatic injury; (2) Free peritoneal fluid on preoperative imaging; (3) Surgical exploration of the abdomen. Setting: A level I trauma center. Results: There were 64 patients, with two peak frequencies between 18-35 and 50-70 years old. Abdominal wall ecchymoses were found in 36 (55\%) of cases. Out of 64 cases 37 (58.7\%) were transportation related, 12 (19\%) caused by human aggression and 10 (16.9\%) by falls. According to the Trauma Score (TS) there were 50 (78.2\%) cases with TS between 14-16, 9 (17.2\%) between $10-13$ and $3(4.8 \%)$ with TS <9. More frequent extraabdominal associated lesions were: head injuries - 38 (58.5\%), thoracic trauma - 34 (52.3\%), orthopedic injuries - 24 (36.9\%). Diagnostic peritoneal lavage was performed in 5 (7.8\%) cases. FAST has a sensibility of $70.21 \%$ and CT scan a sensibility of $100 \%$. Most frequent injured abdominal organs were the spleen - 36 (56.25\%), liver 17 (26.56\%) and mesentery 14 (21.87\%). Laparotomy was performed in $59(92.2 \%)$ of cases, laparoscopy in 2 (3.1\%) of cases and conversion to open surgery in $3(4.7 \%)$ cases. Mortality was $23.43 \%$. We observed several predictive factors for mortality on univariate analysis: haemoglobin $<8 \mathrm{~g} / \mathrm{dl}(\mathrm{p}=0.02)$, haematocrits $<25 \%$ ( $p=0.01)$, hemoperitoneum $>1500 \mathrm{ml}(p=0.04)$, colonic trauma $(p=0.001)$, head $(p=0.01)$ and thoracic injuries $(p=0.04)$. Dedicated trauma surgeons should balance between trauma kinetics details, patients' clinical examination, and diagnostic workup, in an effort to decrease morbidity and mortality secondary to missed injuries or unnecessary laparotomies.
\end{abstract}

Keywords: trauma, hemoperitoneum, free peritoneal fluid

\section{Introduction}

Trauma surgeons are confronted nowadays with various abdominal injuries, with a more and more increased severity, secondary to urban violence and traffic related accidents [1]. In
2020 there is expected death secondary to injuries in about 8.4 million people, trauma being responsible for the majority of the years of potential life lost, more significant than cancer and cardiovascular diseases [2]. At admission, despite a large variety of trauma 
scores, the prognosis is still unpredictable [3]. The posttraumatic hemoperitoneum (PTH) is observed in many intraabdominal organs injuries. These injuries can be managed by a wide variety of techniques, from nonoperative to very aggressive surgical procedures. The purpose of this study is to better define the prognostic value of PTH in the nowadays era of nonoperative management of abdominal lesions, and to correlate it with the current pattern of traumatic injuries.

\section{Material and Methods}

Retrospective study of patients admitted during 24 months. Selections criteria: (1) Traumatic injury; (2) Free peritoneal fluid on preoperative imaging; (3) Surgical exploration of the abdomen. The study was performed in a level I trauma center, with a duration of 24 months. Data collected and analyzed included: demographics, mechanism of injury, trauma scores, prehospital time, time from admission to operating room, clinical exam, blood tests, imaging, intraoperative findings, hospital stay, and mortality. Continuous variables are expressed as mean \pm standard deviation, and the categorical ones as number (percent). In a sample with normal dispersion was used Student t test for comparison of means. Using parametric analysis of variance (ANOVA) tests there were examined several independent samples, normally distributed, to highlight the influence of the considered factor. The probability of rejecting the null hypothesis (statistical significance) was set at 0.05 . For statistical analysis we have used the IBM SPSS Statistics 19 software.

\section{Results}

There were 64 patients with PTH, confirmed by surgical exploration of abdomen. The average age was 35 years, with two peaks frequencies of $30-40$ and $50-60$ years old (Figure 1). We have found a FAST sensibility of $70.21 \%$, and a CT sensibility of $100 \%$ in detecting hemoperitoneum. Diagnostic peritoneal lavage (DPL) was performed in $7.8 \%$ of cases.

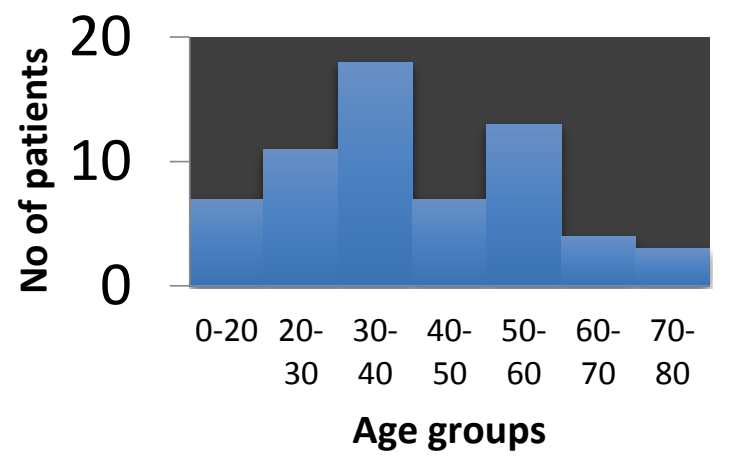

Figure 1 - Histogram - Age distribution

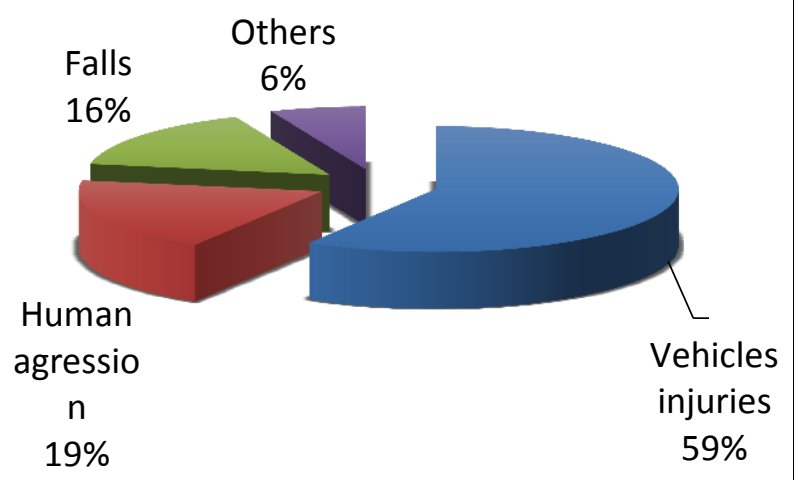

Figure 2 - Trauma etiology

According to the Trauma Score (TS) there were $50(78.2 \%)$ cases with TS between $14-16$, $9(17.2 \%)$ between $10-13$ and $3(4.8 \%)$ with TS $<9$ [3]. Out of 64 cases, $37(58.7 \%)$ were transportation related, $12(19 \%)$ caused by human aggression and $10(16.9 \%)$ by falls (Figure 2). 50 patients had extraabdominal lesions. More frequent extraabdominal associated lesions were: head - 38 (58.5\%), thoracic $-34(52.3 \%)$, and extremity injuries $24(36.9 \%)$.

Abdominal ecchymoses were found in 36 $(55 \%)$ cases. The hemoperitoneum was less than $500 \mathrm{ml}$ in $35 \%$ of cases, between $500-1500 \mathrm{ml}$ in $44 \%$ of cases and greater than $1500 \mathrm{ml}$ in $21 \%$ of cases. The most frequent intraabdominal injuries were spleen, retroperitoneal hematoma and liver ones (Figure 3). 


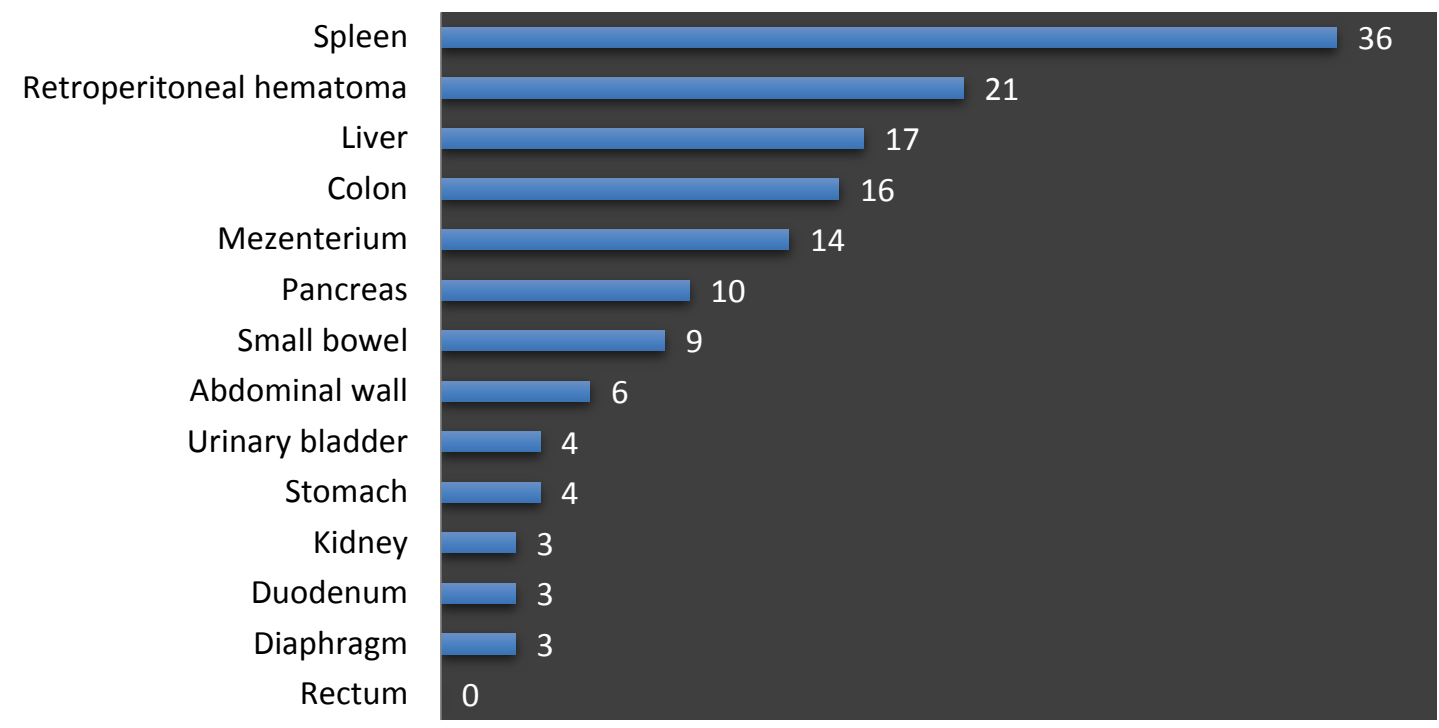

Figure 3: Intraabdominal organ injuries

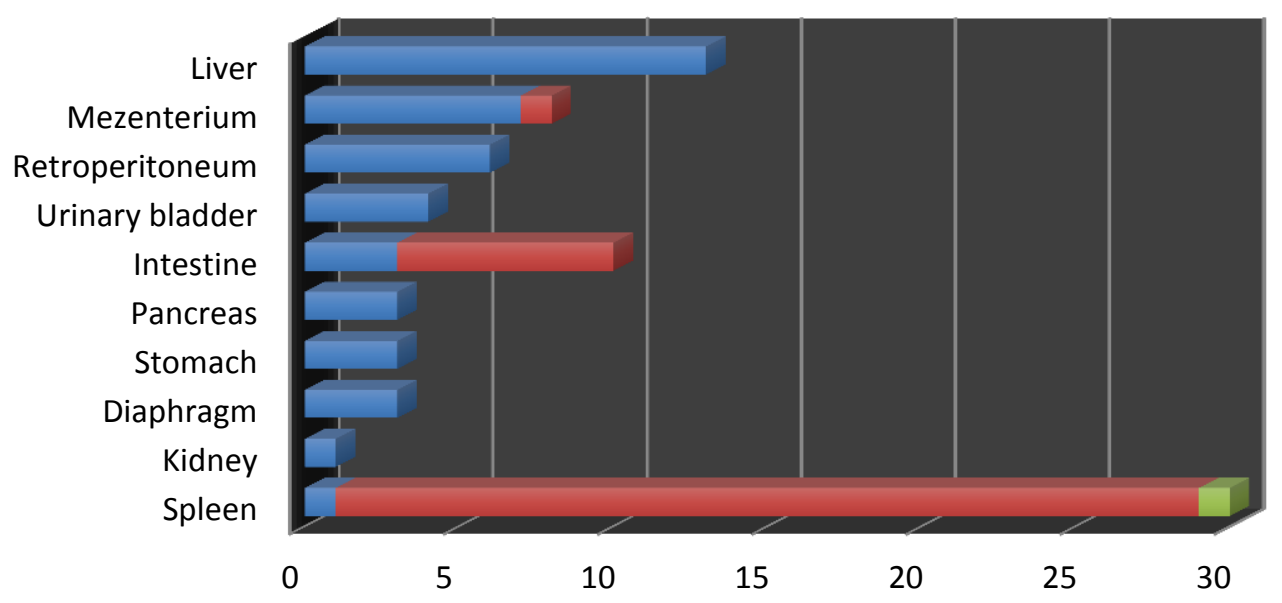

Mechanical, Chemical, Electrical hemostasis Resection $\quad$ Resection with epiplooneal implants

Figure 4: Type of surgical procedures

The surgical approach was by laparotomy in $92 \%$ of cases, by laparoscopy in $3 \%$ of cases and laparoscopy converted to laparotomy in 5\% of cases. The laparotomy was categorized as nontherapeutic in $11 \%$ of cases. For splenic injuries, the most frequent surgical approach was splenectomy and for liver local hemostasis (Figure 4).

There was a mortality of $25 \%$ of cases. On univariate analysis we have observed as predictors of mortality: haemoglobin $<8 \mathrm{~g} / \mathrm{dl}$ ( $\mathrm{p}=0.016)$, haematocrits $<25 \%(\mathrm{p}=0.0163)$, head injuries $(\mathrm{p}=0,007)$, and thoracic injuries $(\mathrm{p}=0,043)$.

\section{Discussions}

The abdominal wall ecchymosis predict a forceful impact, and are usually associated with intraabdominal lesions. According to Perez et al., out of 8 children with a mean age of 8.37 years with safety belt mark, in 7 cases there was an intestinal bursting perforation and in one case a vascular injury of the middle colic vein [4]. Wotherspoon et al. reviewed 99 motor vehicle accident victims, and found seat belt sign in 60 cases [5]. The intestinal injuries were present in 9 out of 60 patients with seat belt mark and in none of 39 patients without this ecchymosis [5]. We also have found a correlation between 
abdominal wall ecchymosis and trauma morbidity.

The advantages of FAST are that it can be used in hemodynamically unstable patients, it takes only $2-3$ minutes, and it is noninvasive [6]. Its disadvantages are that it does not differentiate free fluid from intraperitoneal hemorrhage and may have a false negative result in massive intraperitoneal bleeding. The sensibility of FAST in detecting hemoperitoneum is highly operator dependent, between $28-90 \%$, with a negative predictive value of $78-99 \%$ and a specificity of $95-$ $100 \%$ [7]. Miller et al. concluded that FAST examination in blunt abdominal trauma, in hemodynamically stable patients results in underdiagnosis of injuries [8]. In 359 studied patients, there were 16 true-positives, 22 falsenegatives and 8 false-positives FAST examinations. Six patients with false-negative FAST results required laparotomy for abdominal lesions, and 16 were admitted for nonoperative management. Out of 313 truenegative FAST exams, 19 patients had intraabdominal injuries without hemoperitoneum and 11 patients had retroperitoneal injuries [8]. Natarajan et al. studied 2105 trauma patients and concluded that, due to its low sensitivity, FAST seems not worthwhile for hemodynamically stable patients, and should be reserved only for hemodynamically unstable patients [9]. On the other hand, in hemodynamically unstable patients, even when FAST is performed by the radiologist it has a sensitivity of $62 \%$, a specificity of $96 \%$, a positive predictive value of $84 \%$ and a negative predictive value $89 \%$ [10]. Detection of hemoperitoneum in patients with pelvic fracture and hemodynamic instability is important to differentiate between the necessity of angiography or laparotomy [11]. Friese et al. analyzed 96 patients with pelvic fracture and risk factors for hemorrhage, with age $\geq 55$, hemorrhagic shock, or unstable pelvic fracture. They found a sensitivity for FAST of only $26 \%$ [11]. To predict the need for abdominal hemorrhage control (laparotomy or angiography) in major pelvic fracture, $\mathrm{CT}$ has a positive predictive value of $81 \%$ and a negative predictive value of $96 \%$ for moderate-to-large amount of free abdominal fluid. Varbeek et al concluded that a moderate-to-large amount of free fluid on CT in patients with major pelvic fractures is highly predictive for the presence of abdominal bleeding that requires hemorrhage control [12]. Carter et al. found a sensitivity for FAST of $22 \%$ for hemodynamically stable patients and of $28 \%$ for those hemodynamically unstable [13]. According to the authors, in hemodynamically stable blunt trauma patients, a negative FAST without a CT may result in missed abdominal injuries, and in those hemodynamically unstable, the decision for laparotomy should not be distracted by a negative FAST [13].

Abdominal Computed Tomography is very specific for organ injury and in evidentiating free peritoneal fluid, but it can be used only in hemodynamically stable patients. $12 \%$ of patients with blunt trauma, evaluated by CT, have one or more intraabdominal injuries [14]. There is no consensus about the management of patients with free peritoneal fluid on CT, without solid visceral injuries. GonserHafertepen et al. reviewed 2899 blunt trauma patients evaluated by CT [15]. 156 (5.4\%) of these patients had isolated free peritoneal fluid, 13 being surgically explored: 9 immediate laparotomy and 4 failed nonoperative management. Abdominal tenderness was present in $69 \%$ of surgical cases and in $23 \%$ of nonoperative/nontherapeutic patients ( $\mathrm{p}<$ 0.001). The moderate to large amount of isolated free fluid was more frequent in operative group ( $85 \%$ vs. $8 \%, p<0.001)$. The conclusion of the authors is that blunt trauma patients with moderate to large amounts of free fluid without solid organ injuries on CT and abdominal tenderness should undergo immediate laparotomy. Patients with neither of these findings can be safely observed [15]. Mahmood et al. studied 122 patients with free peritoneal fluid without solid organ injuries [16]. 34 patients underwent laparotomy, in 31 cases this being therapeutic. Small bowel injuries were found in 12 cases, large bowel injuries in 10 cases, mesenteric injuries in 7 cases, small bowel and colon in 1 case, and gangrenous appendix in 1 case [16].

DPL has a $100 \%$ sensibility for hemoperitoneum, but increases the rate of nontherapeutic procedures, especially now, when liver and splenic injuries are treated 
nonoperatively. It has no specificity in detecting injured organ and it is invasive [17].

Velmahos et Kuncir consider that percutaneous diagnostic peritoneal aspiration (DPA) is accurate, rapid, safe and superior to FAST fo the diagnosis of the free peritoneal blood as the source of hemodynamic instability, necessitating immediate laparotomy, especially in blunt multitrauma patients [18]. The authors studied 62 severe blunt trauma patients, with a Injury Severity Score of 32+/- 17, with systolic blood pressure equal to or less than $90 \mathrm{~mm} \mathrm{Hg}$. $35 \%$ of patients required emergency laparotomy and the reported mortality for the entire group was $63 \%$. The sensitivity and specificity of DPA was $89 \%$ and $100 \%$, while for FAST these were $50 \%$ and $95 \%$, respectively [18].

For blunt trauma patients, laparoscopy has no advantage compared with DPL and CT. It increases the percentage of nontherapeutic surgical procedures and seems to have a very low sensibility for small bowel injuries.

Our group evaluated the succes rate of nonoperative management in 207 polytrauma patients [19]. We have found a success rate of $57.9 \%$ in splenic injuries and in $50 \%$ of cases with liver injuries. In traumatic splenic injuries, whenever nonoperative management fails we are using heterotopic splenic autoimplants into the greater omentum [20]. Starting from 2012 our center has implemented a trauma registry, being convinced about its utility in improving patients' care [21].

\section{Conclusions}

The trauma surgeon benefits nowadays from the highly advanced imagistic tools that may offer a detailed picture of trauma injuries. Only a thorough understanding of the trauma kinetics, patient profile, imagistic findings and clinical exam may decrease the morbidity and mortality in trauma patients.

Acknowledgement: This paper was supported by the Sectoral Operational Programme Human Resources Development (SOP HTD), financed by the European Social Fund and by the Romanian Government, under the contract number POSDRU/159/1.5/S/137390 for author
1, Dr. Ionuţ Negoi. All authors have equally contributed equally to this study. The authors have no conflicts to disclose.

\section{References}

[1]Beuran M., Negoi I., Paun S., Runcanu A., Gaspar B., History of trauma care. Chirurgia (Bucharest, Romania : 1990). 2011;106(5):573-80.

[2]Paun S., Beuran M., Negoi I., Runcanu A., Gaspar B.. Trauma--epidemiology: where are we today?. Chirurgia (Bucharest, Romania : 1990). 2011;106(4):439-43.

[3]Beuran M., Negoi I., Paun S., Runcanu A., Gaspar B., Vartic M., Trauma scores: a review of the literature. Chirurgia (Bucharest, Romania : 1990). 2012;107(3):291-7.

[4]Perez Bertolez S., Gaztambide Casellas J., Unda Freire A., Martinez Leon M., Romero Chaparro S., Sanchez Diaz F. Abdominal lesions associated to safety belt mark. Cirugia pediatrica : organo oficial de la Sociedad Espanola de Cirugia Pediatrica. 2009;22(1):15-21.

[5]Wotherspoon S., Chu K., Brown A.F.. Abdominal injury and the seat-belt sign. Emergency medicine (Fremantle, WA). 2001;13(1):61-5.

[6]McKenney M.G., McKenney K.L., Hong J.J., Compton R., Cohn S.M., Kirton O.C., et al. Evaluating blunt abdominal trauma with sonography: a cost analysis. The American surgeon. 2001;67(10):930-4.

[7]Demetriades D., Velmahos G., Technologydriven triage of abdominal trauma: the emerging era of nonoperative management. Annual review of medicine. 2003;54:1-15.

[8]Miller M.T., Pasquale M.D., Bromberg W.J., Wasser T.E., Cox J., Not so FAST. The Journal of trauma. 2003;54(1):52-9; discussion 9-60.

[9]Natarajan B., Gupta P.K., Cemaj S., Sorensen M., Hatzoudis G.I., Forse R.A., FAST scan: is it worth doing in hemodynamically stable blunt trauma patients? Surgery. 2010;148(4):695-700; discussion -1 .

[10]Gaarder C., Kroepelien C.F., Loekke R., Hestnes M., Dormage J.B., Naess P.A., Ultrasound performed by radiologists-confirming the truth about FAST in trauma. The Journal of trauma. 2009;67(2):323-7; discussion 8-9.

[11]Friese R.S., Malekzadeh S., Shafi S., Gentilello L.M., Starr A., Abdominal ultrasound is an unreliable modality for the detection of hemoperitoneum in patients with pelvic fracture. The Journal of trauma. 2007;63(1):97-102.

[12]Verbeek D.O., Zijlstra I.A., Van der Leij C., Ponsen K.J., Van Delden O.M., Goslings J.C., 
Predicting the need for abdominal hemorrhage control in major pelvic fracture patients: the importance of quantifying the amount of free fluid. The journal of trauma and acute care surgery. 2014;76(5):1259-63.

[13]Carter J.W., Falco M.H., Chopko M.S., Flynn Jr W.J., Wiles Iii C.E., Guo W.A., Do we really rely on fast for decision-making in the management of blunt abdominal trauma? Injury. 2014.

[14]Beuran M., Negoi I., Paun S., Runcanu A., Gaspar B., Mechanism of injury--trauma kinetics. What happend? How?. Chirurgia (Bucharest, Romania : 1990). 2012;107(1):7-14.

[15]Gonser-Hafertepen L.N., Davis J.W., Bilello J.F., Ballow S.L., Sue L.P., Cagle K.M., et al. Isolated free fluid on abdominal computed tomography in blunt trauma: watch and wait or operate? Journal of the American College of Surgeons. 2014;219(4):599-605.

[16]Mahmood I., Tawfek Z., Abdelrahman Y., Siddiuqqi T., Abdelrahman H., El-Menyar A., et al. Significance of computed tomography finding of intra-abdominal free fluid without solid organ injury after blunt abdominal trauma: time for laparotomy on demand. World journal of surgery. 2014;38(6):1411-5.
[17]Bellows C.F., Salomone J.P., Nakamura S.K., Choe E.U., Flint L.M., Ferrara J.J., What's black and white and red (read) all over? The bedside interpretation of diagnostic peritoneal lavage fluid. The American surgeon. 1998;64(2):112-8.

[18]Kuncir E.J., Velmahos G.C., Diagnostic peritoneal aspiration--the foster child of DPL: a prospective observational study. International journal of surgery (London, England). 2007;5(3):167-71.

[19]Gaspar B., Negoi I., Paun S., Hostiuc S., Ganescu R., Beuran M., Selective Nonoperative Management of Abdominal Injuries in Polytrauma Patients: a Protocol only for Experienced Trauma Centers. MAEDICA-a Journal of Clinical Medicine. 2014;9(2):168-72.

[20]Chiotoroiu A., Venter D., Negoi I., Vartosu C., Plotogea O., Paun S., et al. Splenic implant assessment in trauma. Chirurgia (Bucharest, Romania : 1990). 2014;109(6):731-40.

[21]Beuran M., Stoica B., Negoi I., Tanase I., Gaspar B., Turculet C., et al. Trauma registry -- a necessity of modern clinical practice. Chirurgia (Bucharest, Romania : 1990). 2014;109(2):157-60. 